\title{
Transmigration of Mandibular Canines - Clinical Implications
}

Preema Melani Pinto', Vijay R Naik², Vikram Pai ${ }^{3}$, Kalpana S J adhav ${ }^{4}$, Siddharth Revankar ${ }^{5}$

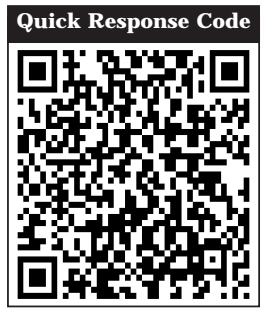

doi: $10.5866 / 2015.7 .10212$

${ }^{1}$ Consultant Orthodontist

Belgaum, India

2Professor \& Head

${ }^{3 \& 5}$ Reader

Department Of Orthodontics and Dentofacial

Orthopaedics, Maratha Mandal's Institute pf Dental

Sciences, Belgaum, Karnataka, India.

${ }^{4}$ Specialist Orthodontist

United Arab Emirates

\section{Article Info:}

Received: J uly 7, 2015

Review Completed: August 6, 2015

Accepted: September 9, 2015

Available Online: J uly, 2015 (www.nacd.in)

(c) NAD, 2015 - All rights reserved

\section{Email for correspondence:}

preemapinto@rocketmail.com

\section{ABSTRACT:}

Transmigration of a mandibular canine across the midline is a rare condition with obscure etiology. Bilateral transmigration is found to be extremely rare. Transmigrated canines have been found to be associated with dental anomalies and pathologies such as cystic lesions and root resorption of the adjacent teeth. The treatment of transmigrated mandibular canine demands clinical expertise. The presence of mandibular canal, mental foramen and the symphyseal bone complicates the surgical removal of these impacted canines. The treatment options vary according to the needs of the individual case and whether the tooth is symptomatic or not. The success of orthodontic treatment relies on the position, bone density and mechanics involved.

Key words: impacted canine; mandibular canine; transmigration.

\section{Introduction:}

The maxillary canines are the commonly impacted teeth in the human dentition next to the third molars. Impaction of mandibular canines is quite rare in comparison to maxillary canines as described by Rohrer, who concluded that impacted canines are 20 times more frequent in maxilla than in the mandible. ${ }^{1}$ In few instances, the mandibular canines have been found to have migrated across the midline to the other side of the mandible and are described as being transmigrated. I $\mathrm{n}$ cases where these teeth tend to erupt, they are usually transposed.

Transmigration of a tooth, in general refers to the event of migration of a tooth away from its site of origin. As is evident from the literature, varying definitions have been attributed to the transmigration of mandibular canine depending on the status of the affected tooth in relation to the midline. ${ }^{2-4}$ 
Numerous theories speculating the aetiology have been put forth but none of which do accurately define the cause of this unique phenomenon. They include heredity, abnormal displacement of the dental Iamina in theembryonic life, axial inclination of erupting canines, retention or premature loss of deciduous canine, inadequate eruption space, supernumerary teeth, excessive length of crown, endocrine disorders, trauma, diet and intrauterine defects. $^{5-9}$

The scope for treatment of these transmigrated canines is very limited. The treatment options include preventive and interceptive treatment, surgical exposure and orthodontic treatment, autotransplantation, surgical removal and radiographic monitoring. ${ }^{10-14}$

The unpredictably unique manifestation of these canines renders the treatment difficult if not impossible. Each treatment possibility presents with its own merits and demerits. The literature doesn't giveany insight intothe intricacies of the treatment techniques. The purpose of this article is to discuss the possible clinical implications while treating the transmigration. Four cases of transmigration are presented in this context.

\section{Case reports:}

Case 1: A 16 year old male patient reported with the chief complaint of forwardly placed upper front teeth (Figure 1 and 2). Medical history was non contributory. The patient had a dental history of undergoing orthodontic treatment previously which he discontinued midway. Clinical examination revealed that all permanent teeth had erupted except the two mandibular canines and mandibular left third molar. The patient had a Angle's Class II division 1 malocd usion with a $100 \%$ deep bite, an overjet of $10 \mathrm{~mm}$ and posterior scissor bite. Theright lateral incisor had a talon's cusp. The panoramic radiograph showed the mandibular right and left canines lying horizontally beneath the apices of mandibular anterior teeth. The crowns of the impacted canines were pointing towards the contra-lateral mental foramina (Figure 3). The lateral cephalogram depicted a small radiopaque mass in the symphysis region (Figure 4). No pathologic finding was associated with the transmigrated teeth. The mandibular left third molar was horizontally impacted.

Case 2: Clinical examination of a 19 year old male patient who presented with the chief complaint of irregularly placed lower front teeth revealed class I molar relation and a retained mandibular left deciduous canine. The permanent left canine was upright and erupted in the midline, labial to the mandibular right central incisor (Figure 5 and 6). No pathologic finding was associated with the transmigrated tooth.

Case 3: A 30 year old male patient presented with the chief complaint of missing upper front teeth. On clinical examination, hewas found to have a class II molar relation, 100\% deep bite, scissor bite on left side, congenitally missing maxillary lateral incisors and over retained mandibular right deciduous canine (Figure 7). Panoramic radiograph revealed obliquely impacted mandibular right permanent canine at the midline (Figure 8). No pathologic finding was associated with the transmigrated tooth

Case 4: A 15 year old male patient presented with the chief complaint of irregularly placed lower front teeth. On clinical examination, he had a class I molar relation, transmigrated and transposed mandibular canines. Theleft permanent mandibular canine had erupted in the midline, with the other permanent canine lying adjacent to it on the right side (Figure 9 and 10). In the strict sense, the right canine couldn't be termed as transmigrated. No pathologic finding was associated with the transmigrated tooth.

\section{Discussion:}

Mupparapu classified mandibular canine transmigration depending on its path of deviation into five types. Type 1: Canine positioned mesioangularly across the midline within the jaw bone, labial or lingual to anterior teeth, and the crown portion of the tooth crossing the midline (45.6\%). Type 2: Canine horizontally impacted near the inferior border of the mandible below the apices of 


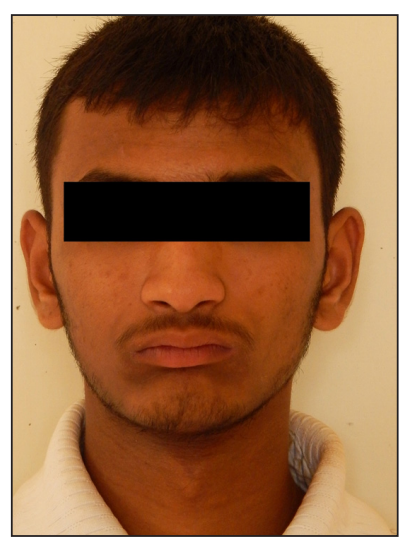

Figure 1: Extra-oral frontal view of case 1 .

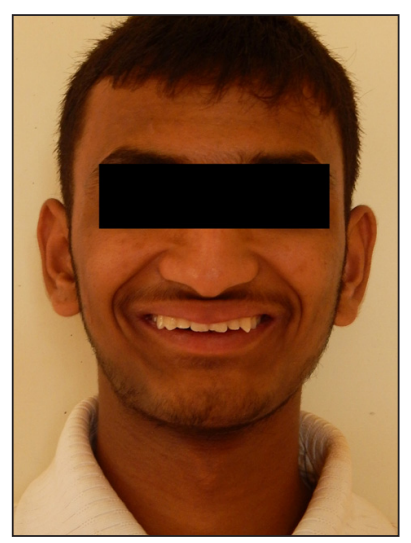

Figure 2: Extra-oral frontal smiling view of case 1 .

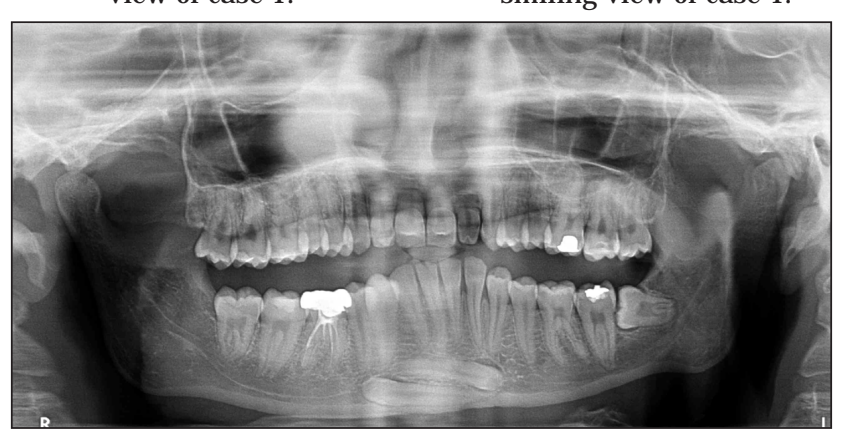

Figure 3: OPG showing transmigrated canines impacted horizontally in the midline of case 1.

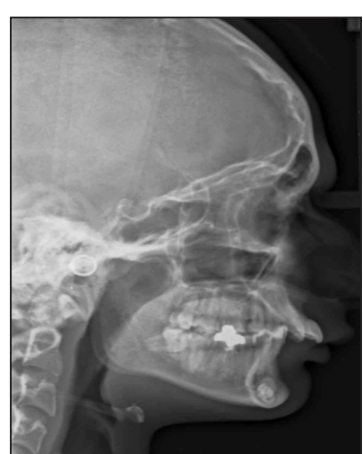

Figure 4: Lateral Cephalogram showing the transmigrated canines at the symphysis as a radiopaque mass of case 1 .

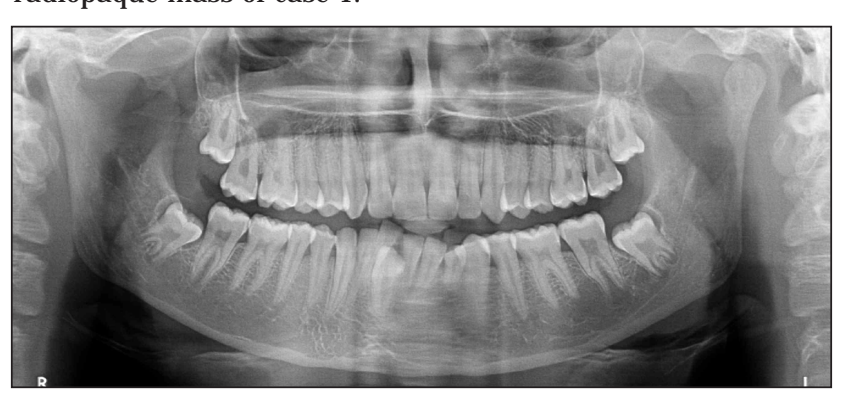

Figure 6: OPG showing 33 overlapping the image of 41 in case 2.

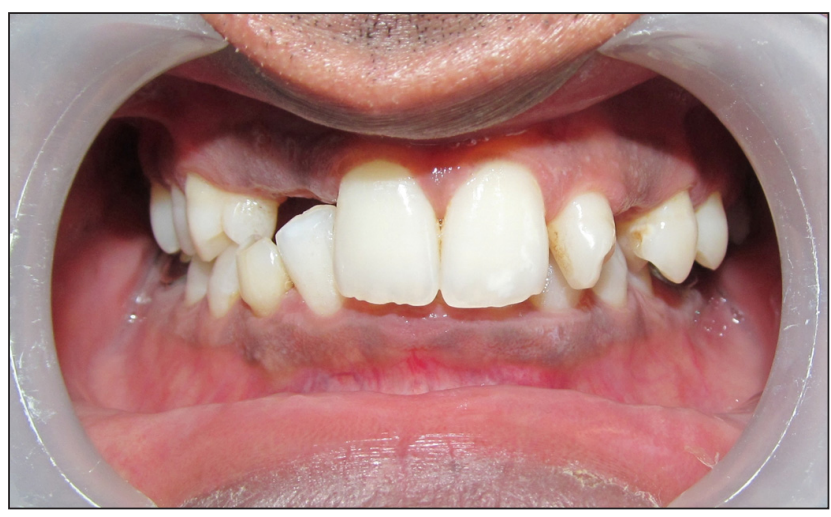

Figure 7: Intra-oral frontal view of case 3.

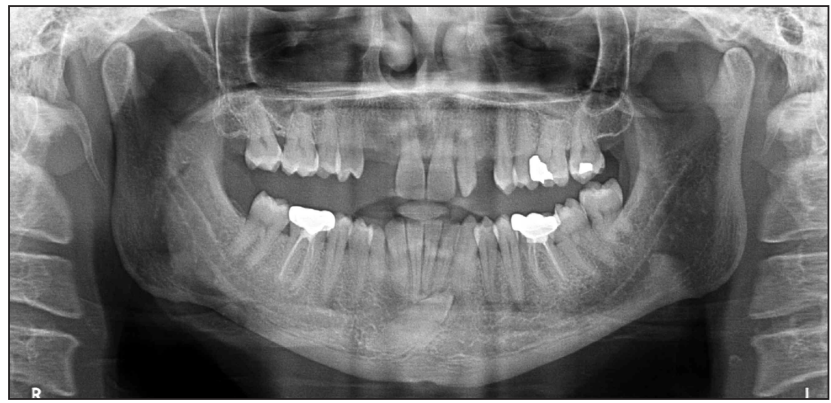

Figure 8: OPG showing obliquely placed 43 with the crown crossing the mandibular midline in case 3.

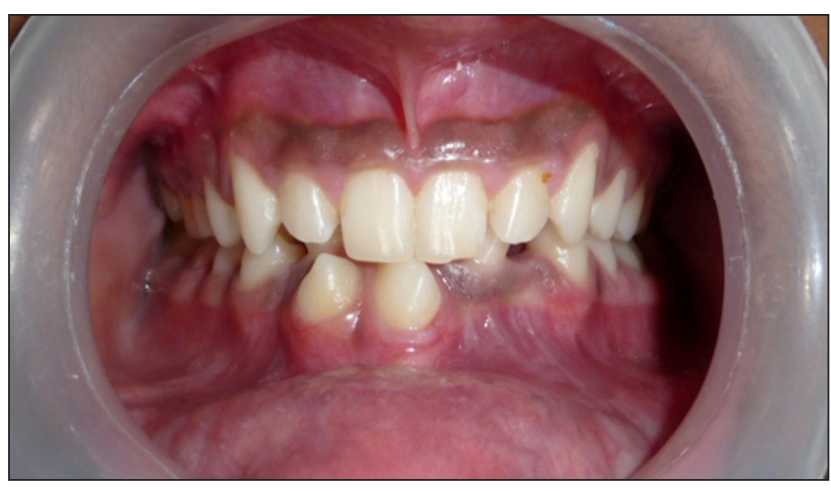

Figure 9: Intra-oral view of the mandibular canines lying adjacent to each other in case 4.

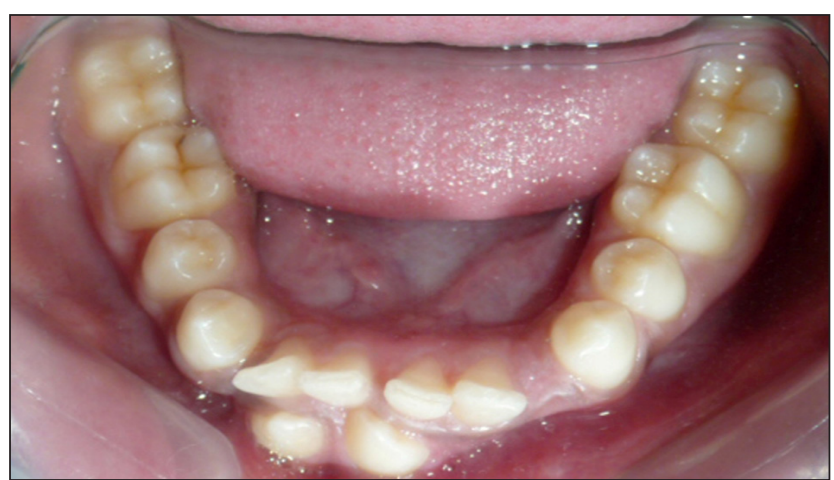

Figure 10: Mandibular occlusal view of case 4. 
the incisors (20\%). Type 3: Canine erupting either mesial or distal to the opposite canine (14\%). Type 4: Canine horizontally impacted near the inferior border of the mandible below the apices of either premolars or molars on the oppositeside (17\%). Type 5: Canine positioned vertically in the midline (the long axis of the tooth crossing the midline) irrespective of eruption status (1.5\%). ${ }^{15}$

The first case reported in this paper belonged to Mupparapu classification type 2 , whose position is unfavourable to attempt orthodontic traction (Figure 3). Surgical removal leaves a temporary large bony defect and is associated with risks of iatrogenic fracture of the mandible and injury to the elements of mandibular canal. Since the teeth are asymptomatic, periodic radiographic monitoring is being carried out in conjunction with the comprehensive orthodontic treatment that the patient is receiving for his malocclusion. Furthermore, the significance of periodic observation is emphasized by the fact that the affected canines lie in close proximity to the roots of mandibular incisors because of which, during orthodontic tooth movement, there may be possibilities of root resorption of mandibular incisors and/or pathologic changes in relation to thesleeping canines. As the patient presents with $100 \%$ deep bite, the possible treatment options are intrusion of the maxillary or mandibular incisors. Intrusion of maxillary incisors could be carried out but at the expense of soft tissue balance since the patient has zero incisor exposure at rest and the intrusion of mandibular incisors is complicated by the precarious location of the transmigrated canines.

The second case belongs to the Mupparapu classification type 5. This transmigration is well treated by extraction of 33. Space discrepancy renders the alignment of the canine quite difficult. Orthodontic alignment, if possible, has to be done following carefully planned extractions. However, this mode of treatment seems to be cumbersome given the ectopic position of the transmigrated canine which in itself warrants its extraction. F urthermore, since the canine needs to be aligned at the midline itself, transmigrated canine crown should be sequentially contoured to resemble mandibular central incisor. Conversion of canine into an incisor requires removal of a substantial amount of crown structure which may necessitate intentional root canal therapy followed by a crown. Another major drawback is that a canine guided occlusion cannot be established. Also, the canine is vulnerable for root dehiscence because of the narrow distance between the labial and lingual cortical plate. In a similar case treated by Brezniak, Yehuda and Shapira gingival recession was found on the labial side of the treated canine. ${ }^{16}$

The third case belongs to the Mupparapu classification type 1 . The root of the affected canine lies in a favourable position but the success of orthodontic traction to get the tooth into the arch is questionable due to two factors. Firstly the exact position of the canine in the sagittal plane needs to be determined. A labially positioned tooth is amenable for surgical exposure and bonding attachments. Secondly the proximity of the transmigrated canine to the roots of lower central incisors creates complications as discussed earlier. Surgical removal may be considered.

The fourth case belongs to the Mupparapu classification type 5. According to the classification, the mandibular left canine alone can be termed as transmigrated. The migration of mandibular right canine seems to have been obstructed by the left canine. Considering the space deficiency in the mandibular arch, extraction of both the canines was carried out and the first premolars were converted into canines. In a scenario where there was adequate space in the lower arch, orthodontic traction of the right canine could have been an option since it was positioned at a shorter distance without actually having crossed the midline. The left canine could have been treated similar to case number 2 . However, this approach would require longer treatment duration and lighter forces as the tooth is moved through dense cortical bone.

\section{Conclusion:}

In recent years, many cases of transmigration of mandibular canines have been documented. The corrective treatment of these canines is debatable 
and quite challenging. When the impacted teeth aren't removed, care has to be taken not to induce pathologic changes. Maintaining the health of the periodontium of the transmigrated tooth as well as the adjacent teeth is critical while attempting orthodontic traction. Root torqueing in specific cases should be planned prior to initiation of orthodontic treatment to place the root in trabecular bone. latrogenic damage can be best avoided by careful treatment planning with due consideration to the clinical implications of the particular case. Though early detection and treatment is suggested in the literature, evidence is lacking in support of interceptive measures.

\section{References}

1. Rohrer A. Displaced and impacted canines. Orthod Oral Surg Int J 1929; 15:1002-1004.

2. Tarsitano J J, Wooten J W, Burditt J T. Transmigration of non erupted mandibular canines: report of cases. J Am Dent Assoc. 1971; 82:1395-1397.

3. J avid B. Transmigration of impacted mandibular cuspids. Int J Oral Surg 1985; 14:547-549.

4. J oshi MR. Transmigrant mandibular canines: a record of 28 cases and a retrospective review of the literature. Angle Orthod. 2001; 71:12-22.

5. Nodine AM. Aberrant teeth, their history, causes and treatment. Dent I tems I nterest. 1943; 65:440-451.
6. Shapira Y, Mischler WA, Kuftinec MM. The displaced mandibular canine. ASDC J Dent Child 1982; 49(5):362364.

7. Pippi R, Kaitsas R. Mandibular canine transmigration: aethiopathogenetic aspects and six new reported cases. Oral Surg 2008; 1:78-83.

8. Ryan FS, Batra P, Witherow H, Calvert M. Transmigration of a maxillary canine. A case report. Prim Dent Care 2005; 12(2):70-72.

9. Mitchell L. Displacement of a mandibular canine following fracture of the mandible. Br Dent J 1993; 174(11):417-418.

10. Taguchi $\mathrm{Y}$, Kurol J, Kobayashi H, Noda T. Eruption disturbances of mandibular permanent canines in J apanese children. International J ournal of Paediatric Dentistry 2001; 11(2): 98-102.

11. Vichi $M$, Franchi $L$. The transmigration of the permanent lower canine. Minerva Stomatol. 1991; 40:579-589.

12. Wertz RA. Treatment of transmigrated mandibular canines. Am J Orthod Dentofacial Orthop 1994; 106:419-427.

13. Kumar S, Urala AS, Kamath AT, J ayaswal. P, Valiathan. A. Unusual intraosseous transmigration of impacted tooth. I maging Science in Dentistry 2012; 42: 47-54.

14. Howard RD. Theanomalous mandibular canine. Br J Orthod 1976; 3(2):117-121.

15. Mupparapu M. Patterns of intra-osseous transmigration and ectopic eruption of mandibular canines: review of literature and report of nine additional cases. Dentomaxillofac Radiol 2002; 31(6):355-360.

16. Brezniak N, Ben-Yehuda A, Shapira Y. Unusual mandibular caninetransposition: a case report. AmJ Orthod Dentofacial Orthop 1993; 104:91-94.

\section{Gain quick access to our journal online} View our journal at www.nacd.in 